\title{
Directed Self-Assembly of Trimeric DNA-Bindingchiral Miniprotein Helicates
}

\author{
Jacobo Gómez-González ${ }^{1}$, Diego G. Peña ${ }^{2}$, Ghofrane Barka ${ }^{1}$, Giuseppe Sciortino ${ }^{3,4}$, \\ Jean-Didier Maréchal ${ }^{3 *}$, Miguel Vázquez López ${ }^{1 *}$ and M. Eugenio Vázquez ${ }^{2 *}$
}

${ }^{1}$ Centro Singular de Investigación en Química Biolóxica e Materiais Moleculares (CiQUS), Departamento de Química Inorgánica, Universidade de Santiago de Compostela, Santiago de Compostela, Spain, ${ }^{2}$ Centro Singular de Investigación en Química Biolóxica e Materiais Moleculares (CiQUS), Departamento de Química Orgánica, Universidade de Santiago de Compostela, Santiago de Compostela, Spain, ${ }^{3}$ Departament de Química, Universitat Autònoma de Barcelona, Cerdanyola, Spain, ${ }^{4}$ Dipartimento di Chimica e Farmacia, Università di Sassari, Sassari, Italy

We propose that peptides are highly versatile platforms for the precise design of supramolecular metal architectures, and particularly, for the controlled assembly of helicates. In this context, we show that the bacteriophage T4 Fibritin foldon (T4Ff)

OPEN ACCESS

Edited by:

Angela Casini,

Cardiff University, United Kingdom

Reviewed by:

Olga Iranzo

Center National de la Recherche Scientifique Marseille, France

Guzman Gil-Ramirez,

University of Lincoln, United Kingdom

${ }^{*}$ Correspondence:

Jean-Didier Maréchal jeandidier.marechal@uab.cat

Miguel Vázquez López miguel.vazquez.lopez@usc.es

M. Eugenio Vázquez eugenio.vazquez@usc.es

Specialty section:

This article was submitted to Supramolecular Chemistry, a section of the journal Frontiers in Chemistry

Received: 20 August 2018 Accepted: 09 October 2018 Published: 30 October 2018

Citation:

Gómez-González J, Peña DG, Barka G, Sciortino G, Maréchal J-D, Vázquez López $M$ and Vázquez ME (2018) Directed Self-Assembly of Trimeric DNA-Bindingchiral Miniprotein Helicates. Front. Chem. 6:520 doi: 10.3389/fchem.2018.00520 can been engineered on its $\mathrm{N}$-terminus with metal-chelating 2,2'-bipyridine units that stereoselectively assemble in the presence of Fe(II) into parallel, three-stranded peptide helicates with preferred helical orientation. Modeling studies support the proposed self-assembly and the stability of the final helicate. Furthermore, we show that these designed mini-metalloproteins selectively recognize three-way DNA junctions over double-stranded DNA.

Keywords: metallopeptide, self-assembly water, DNA recognition, enantioselectivity, peptide motifs, coordination chemistry

\section{INTRODUCTION}

Peptides are excellent supramolecular building blocks that encode precise structural and functional information within their amino acid sequence. Accordingly, researchers have explored diverse peptide motifs, such as coiled-coils, $\beta$-hairpins, or peptide amphiphiles, as the basis of biofunctional devices and materials (Matsuura et al., 2005, 2010; Gazit, 2007; Ulijn and Smith, 2008; Apostolovic et al., 2010; Robson Marsden and Kros, 2010; Boyle and Woolfson, 2011; Lai et al., 2012; Pazos et al., 2016). Curiously, despite the enormous potential for controlling stereochemistry, nuclearity and stoichiometry, the controlled supramolecular assembly of inorganic complexes with peptide motifs has been somewhat overlooked, and only a handful of systems based on modified coiled-coil motifs have been reported (Lieberman and Sasaki, 1991; Ghadiri et al., 1992; Li et al., 2000; Peacock et al., 2012; Ball, 2013; Berwick et al., 2014; Luo et al., 2016). On the other hand, helicates are discrete metal complexes in which one or more organic ligands are coiled around-and coordinating-two or more metal ions (Piguet et al., 1997; Albrecht, 2001, 2005) as a result of ligand coiling, helicates are inherently chiral species that can appear as two enantiomers according to the orientation in which the ligands twist around the helical axis defined by the metal centers. Besides their intrinsic interest in basic supramolecular chemistry, helicates have shown promising DNA-binding properties that have been associated with antimicrobial and antitumoral effects (Howson et al., 2012; Kaner et al., 2015). However, more than 20 years after the pioneering studies by Prof. Jean-Marie Lehn (Lehn et al., 1987; Ulijn and Smith, 2008), helicates are still not viable alternatives to traditional 
DNA-binding agents. The slow development in the applied chemistry of metal helicates ultimately derives from the shortcomings associated with the classic synthetic approaches with organic ligands that complicate the structural control of the final helicates (i.e., oligomerization state, relative orientation of asymmetric ligands, supramolecular helicity) and hampers their efficient structural and functional optimization. Indeed, despite some noteworthy examples (Haino et al., 2009; Cardo et al., 2011; Howson et al., 2012; Chen et al., 2017; Mitchell et al., 2017; Guan et al., 2018), no general approach for the efficient and versatile stereoselective synthesis of helicates is yet available, making of these systems a challenging test case to demonstrate the potential of peptides for the controlled assembly of metallostructures.

Our strategy relied in the selection of a synthetically-accessible and structurally well-defined trimeric peptide domain as scaffold for the programmed assembly of the helicate. As an alternative (and orthogonal) platform to the ubiquitous leucine zippers, we focused our attention on the C-terminal domain of the bacteriophage T4 Fibritin foldon (T4Ff), a trimeric $\beta$-propellerlike structure formed by the self-assembly of a short 27-amino acid peptide (Tao et al., 1997; Papanikolopoulou et al., 2004; Habazettl et al., 2009). The intrinsic stability and structural resilience of the T4Ff scaffold has been exploited for the stabilization of trimeric structures of a number of peptides and engineered proteins (Stetefeld et al., 2003; Du et al., 2011; Berthelmann et al., 2014; Kobayashi et al., 2015), and given those precedents we envisioned that the T4Ff could also be used as a robust platform for the programmed assembly of chiral dinuclear helicates, thus offering an alternative for the integration of coordination and peptide chemistry beyond other widely explored peptide scaffolds.

\section{MATERIALS AND METHODS}

\section{General}

All reagents were acquired from the regular chemical suppliers. All solvents were dry and synthesis grade, unless specifically noted $\left(\mathrm{NH}_{4}\right) \mathrm{Fe}_{2}\left(\mathrm{SO}_{4}\right)_{2} \bullet 6 \mathrm{H}_{2} \mathrm{O}$ salt from Sigma-Aldrich was used as $\mathrm{Fe}(\mathrm{II})$ ion source. Reactions were followed by analytical UHPLC-MS with an Agilent 1200 series LC/MS using a SB C18 $(1.8 \mu \mathrm{m}, 2.1 \times 50 \mathrm{~mm})$ analytical column from Phenomenex. Standard conditions for analytical UHPLC consisted on a linear gradient from 5 to $95 \%$ of solvent $\mathrm{B}$ for $12 \mathrm{~min}$ at a flow rate of $0.35 \mathrm{~mL} / \mathrm{min}$ (A: water with $0.1 \% \mathrm{TFA}, \mathrm{B}$ : acetonitrile with $0.1 \%$ TFA). Compounds were detected by UV absorption at 222, 270, and $330 \mathrm{~nm}$. Electrospray Ionization Mass Spectrometry (ESI/MS) was performed with an Agilent 6120 Quadrupole LC/MS model in positive scan mode using direct injection of the purified peptide solution into the MS detector.

\section{Computational Methods}

The model for the $\Lambda \Lambda-\left[(\boldsymbol{\beta A l a B p y})_{2}-\mathbf{T} 4 \mathbf{F f}\right]_{3} \mathrm{Fe}_{2}^{+4}$ helicate was built with UCSF chimera1.12 (Pettersen et al., 2004), starting from the NMR resolved structure of the trimeric Foldon of the T4 phagehead fibritin (PDB code: 1RFO) mutating the carboxyl C-Termini to amide groups (see Results and Discussion section). Based on previous work, the model of
$\Lambda \Lambda-\left[(\boldsymbol{\beta A l a B p y})_{2}-\mathbf{T} 4 \mathbf{F f}\right]_{3} \mathrm{Fe}_{2}^{+4}$ helicate were built connecting the $\mathrm{N}$-termini of the T4Ff peptides. Molecular Dynamics (MD) simulations were set up with the xleap, solvating the model with a box of pre-equilibrated TIP3P water molecules and the total charge was balanced with $\mathrm{Cl}^{-}$ions (ions94.lib library). The AMBER14SB force field was used for standard residues (Hornak, Abel, Okur, Strockbine, Roitberg and Simmerling., 2006), while the GAFF force field was adopted for the remaining atoms. Fe-bonding force constants and equilibrium parameters were obtained through the Seminario method, using Gaussian09 to compute the geometry and harmonic frequencies at DFT level (Frisch et al., 2010), with the B3LYP functional (Yanai et al., 2004), combined with scalar-relativistic Stuttgart-Dresden SDD pseudopotential and its associated double- $\zeta$ basis plus a set of $f$ polarization functions for the metal ion (Ehlers et al., 1993). The 6-31G(d,p) basis set was used for H, C, O, and N. Point charges were derived using the RESP (Restrained ElectroStatic Potential) model (Bayly et al., 1993). The force field building operations were carried out using the MCPB.py (Li and Merz, 2016). The solvent and the whole system were sequentially submitted to 3,000 energy minimization steps to relax possible steric clashes. Then, thermalization of water molecules and side chains was achieved by increasing the temperature from $100 \mathrm{~K}$ up to $300 \mathrm{~K}$. MD simulations under periodic boundary conditions were carried out during 100 ns with OpenMM engine through OMMProtocol (Eastman et al., 2017; Pedregal et al., 2018). Analysis of the trajectories was carried out by means of cpptraj implemented in ambertools16 (Case et al., 2016).

\section{Solid-Phase Peptide Synthesis (SPPS)}

All peptide synthesis reagents, as well as the Fmoc amino acid derivatives were purchased from GL Biochem (Shanghai) Ltd., Fmoc- $\beta$-Ala-OH was from Sigma Aldrich. C-terminal amide natural T4Ff peptides were synthesized following standard Fmocpeptide synthesis protocols on a $0.1 \mathrm{mmol}$ scale using a 0.5 $\mathrm{mmol} / \mathrm{g}$ loading H-Rink amide ChemMatrix resin (35-100 mesh) from Sigma Aldrich with a Liberty Lite automatic microwave assisted peptide synthesizer from CEM Corporation. The amino acids were coupled in 5-fold excess using oxyme as an activating agent. Couplings were conducted for $4 \mathrm{~min}$ at $90^{\circ} \mathrm{C}$. Deprotection of the temporal Fmoc protecting group was performed by treating the resin with $20 \%$ piperidine in DMF for $1 \mathrm{~min}$ at $75^{\circ} \mathrm{C}$. Once the synthesis is finished, the peptide was acetylated with a solution of $0.8 \mathrm{ml} \mathrm{AcOH}, 2 \mathrm{ml}$ of DIEA/DMF $(0.2 \mathrm{M})$ and $3.2 \mathrm{ml}$ of DMF. The last non-natural Fmoc- $\beta$-Ala-Bpy-OH residues were coupled by hand in 4-fold excess using HATU as activating agent. Each amino acid was activated for $1 \mathrm{~min}$ in DIEA/DMF 0.2 M before being added onto the resin. These manual couplings were conducted for $60 \mathrm{~min}$. Deprotection of the temporal Fmoc protecting group was performed by treating the resin with $20 \%$ piperidine in DMF for $20 \mathrm{~min}$. Cleavage and deprotection of the peptide were simultaneously performed using standard conditions by incubating the resin for $2.5 \mathrm{~h}$ with an acidic mixture containing $50 \mu \mathrm{L} \mathrm{CH}_{2} \mathrm{Cl}_{2}, 25 \mu \mathrm{L}$ of $\mathrm{H}_{2} \mathrm{O}, 25$ $\mu \mathrm{L}$ of TIS (triisopropylsilane), and 900 TFA $\mu \mathrm{L}$. The resin was filtered, and the TFA filtrate was concentrated under a nitrogen stream to an approximate volume of $1 \mathrm{~mL}$, and then added onto 
ice-cold diethyl ether $(20 \mathrm{~mL})$. After $10-30 \mathrm{~min}$, the precipitate was centrifuged and washed again with $5 \mathrm{~mL}$ of ice-cold ether. The solid residue was dried under argon and redissolved in acetonitrile/water 1:1 (2-5 mL) and purified by semi-preparative RP-HPLC.

Peptides were purified by preparative RP-HPLC with an Waters 1500 series Liquid Chromatograph using a Sunfire Prep C18 OBD $(5 \mu \mathrm{m}, 19 \times 150 \mathrm{~mm})$ reverse-phase column from Waters. Standard conditions for analytical and preparative RP- HPLC consisted on an isocratic regime during the first $2 \mathrm{~min}$, followed by a linear gradient from 15 to $75 \%$ of solvent B for $30 \mathrm{~min}$ (A: water $0.1 \%$ TFA, B: acetonitrile $0.1 \%$ TFA). Compounds were detected by UV absorption (222 nm) and by ESI/MS. The fractions containing the products were freeze-dried and their identity was confirmed by ESI/MS and MALDI-TOF. Matrix-assisted laser desorption/ionization mass spectrometry (MALDI/MS) was performed with a Bruker Autoflex MALDI/TOF model in positive scan mode by direct irradiation of the matrix-absorbed peptide.

\section{Spectroscopic Measurements}

UV measurements were made in a Jasco V-630 spectrophotometer coupled to a Jasco ETC-717 temperature controller, using a standard Hellma semi-micro cuvette (108.002QS) with a light path of $10 \mathrm{~mm}$. Measurements were made at $20^{\circ} \mathrm{C}$. Luminescence experiments were made with a Varian Cary Eclipse Fluorescence Spectophotometer coupled to a Cary Single Cell peltier accessory (Agilent Technologies) temperature controller. All measurements were made with a Hellma semi-micro cuvette (108F-QS) at $20^{\circ} \mathrm{C}$. Circular dichroism measurements were made with a Jasco J-715 coupled to a Neslab RTE-111 termostated water bath, using a Hellma 100-QS cuvette (2 mm light pass).

\section{Electrophoretic Mobility Shift Assays}

EMSA were performed with a BioRad Mini Protean gel system, powered by an electrophoresis power supplies PowerPac Basic model, maximum power $150 \mathrm{~V}$, frequency $50-60 \mathrm{~Hz}$ at $140 \mathrm{~V}$ (constant $\mathrm{V}$ ). Binding reactions were performed over $30 \mathrm{~min}$ in $1.8 \mathrm{mM}$ Tris- $\mathrm{HCl}$ (pH 7.5), $90 \mathrm{mM} \mathrm{KCl}, 1.8 \mathrm{mM} \mathrm{MgCl}_{2}, 0.2 \mathrm{mM}$ TCEP, $9 \%$ glycerol, $0.11 \mathrm{mg} / \mathrm{mL}$ BSA, and 2.2\% NP-40. For the experiments we used $200 \mathrm{nM}$ of the DNAs (twDNA and dsDNA), and a total incubation volume of $20 \mu \mathrm{L}$. After incubation for $30 \mathrm{~min}$ at room temperature, products were resolved by PAGE using a $10 \%$ non-denaturing polyacrylamide gel and $1 \times \mathrm{TBE}$ buffer ( $0.445 \mathrm{M}$ Tris, $0.445 \mathrm{M}$ Boric acid) for $35 \mathrm{~min}$ at $25^{\circ} \mathrm{C}$, and analyzed by staining with SyBrGold (Molecular Probes: $5 \mu \mathrm{L}$ in $50 \mathrm{~mL}$ of $0.5 \times \mathrm{TBE}$ ) for $10 \mathrm{~min}$ and visualized by fluorescence (BioRad GelDoc XR+ molecular imager).

\section{RESULTS AND DISCUSSION}

As metal-chelating unit we chose $2,2^{\prime}$-bipyridine, a ligand that has been extensively used in coordination chemistry and yields stable complexes with a variety of metal ions (Kaes et al., 2000). Furthermore, we have previously described an Fmocprotected $2,2^{\prime}$-bipyridine dipeptide derivative that can be readily implemented into standard Fmoc solid-phase peptide synthesis (SPPS) protocols, and have showed that the structure of this chelating unit, in which the 2,2'-bipyridine ligand is integrated in the peptide backbone, effectively couples the conformational preferences of the peptide chain with the geometry of the resulting metal complexes (Rama et al., 2012; Gamba et al., 2013, 2014, 2016; Salvadó et al., 2016).

The chelating 2,2' -bipyridine residue was obtained following an optimized synthetic route (Rama et al., 2012), based on the work carried out by the Newkome and Imperiali groups (Newkome et al., 1997; Torrado et al., 1998). The key step in the synthesis being the desymmetrization of a diethyl $\left[1,1^{\prime}\right.$-biphenyl $]-4,4^{\prime}$-dicarboxylate intermediate with hydrazine monohydrate under conditions that allow the selective precipitation of the monocarbohydrazide, which is oxidized into the corresponding azyl azide, and then transformed into a carbamate through a Curtius rearrangement (Rama et al., 2012). Simultaneous hydrolysis of the carbamate and the ester group gives the desired bipyridine amino acid, which is derivatized in the form of a dipeptide to obtain the Fmoc- $\beta$ AlaBpy-OH building block for increased solubility, stability, and solubility that allow its use following standard solid-phase peptide synthesis protocols (Ishida et al., 2006).

Inspection of the structure of T4Ff (PDB IDs $4 \mathrm{NCU}$ or 1RFO; Güthe et al., 2004; Berthelmann et al., 2014) showed that the $\mathrm{N}$-terminal Gly residues are relatively close to each other and could accommodate the chelating 2,2'-bipyridine units without noticeable distortion of the T4Ff scaffold upon metal coordination. Moreover, we envisioned that the natural twist of the N-terminal polyproline helices in the folded T4Ff trimer should induce a $\Lambda \Lambda$-configuration ( $M$ helicity) on its derived helicate (Tao et al., 1997), which would be the preferred chirality for the efficient recognition of three-way DNA junctions (Oleksy et al., 2006; Gamba et al., 2016). Therefore, we synthesized the desired ( $\boldsymbol{\beta A l a B p y})_{2}$-T4Ff helicate precursor ligand following standard Fmoc SPPS methods as outlined in Figure 1 (Coin et al., 2007). The final peptide ligand was purified by HPLC and its identity confirmed by ESI-MS.

Having at hand the desired peptides we proceeded with the study of their metal binding properties. Surprisingly, while $2,2^{\prime}$-bipyridine is weakly emissive, and is even considered non-fluorescent (Dhanya and Bhattacharyya, 1992; Yagi et al., $1994)$, we found that the asymmetric $5^{\prime}$-amido-[2,2'-bipyridine]5 -carboxamide unit within the $\beta$ AlaBpy residue was highly emissive, displaying intense band at c.a. $420 \mathrm{~nm}$ with a quantum yield of 0.37 (Dong et al., 2017). Additionally, the emission was quenched by coordination to Fe(II) ions, which could be exploited to monitor the formation of the $\beta$-annulus helicate. Thus, we recorded the emission spectra of a $3 \mu \mathrm{M}$ solution $(9 \mu \mathrm{M}$ monomer $)$ of $\left[(\boldsymbol{\beta A l a B p y})_{2}-\mathbf{T} 4 \mathbf{F f}\right]_{3}$ in phosphate buffer $(1 \mathrm{mM}, \mathrm{pH} 6.5)$ in the presence of increasing concentrations of $\left(\mathrm{NH}_{4}\right)_{2} \mathrm{Fe}\left(\mathrm{SO}_{4}\right)_{2} \bullet 6 \mathrm{H}_{2} \mathrm{O}$ (Mohr salt) as source of $\mathrm{Fe}(\mathrm{II})$ ions $(\lambda$ exc $=305 \mathrm{~nm}$ ), and observed a concentration-dependent quenching of the emission intensity of the bipyridine ligands. The emission intensity profile of the titration $\mathrm{nm}$ could be fitted to a 1:2 binding mode with dissociation constants for the first, and second iron coordination of $K_{D 1}=5.5 \pm 3.3 \mu \mathrm{M}$ and a 
A

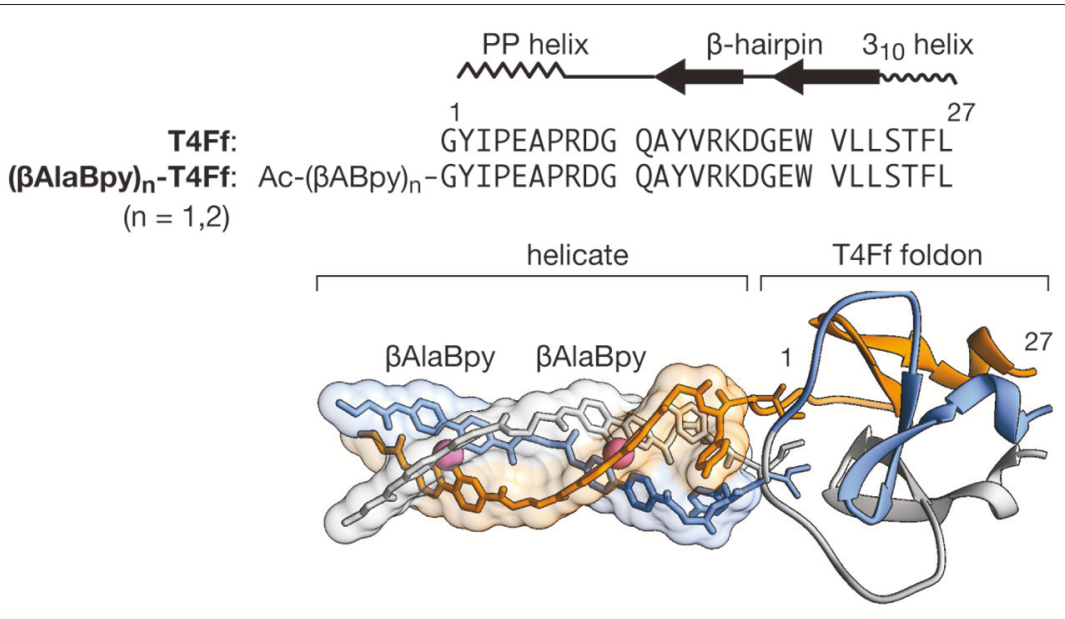

B

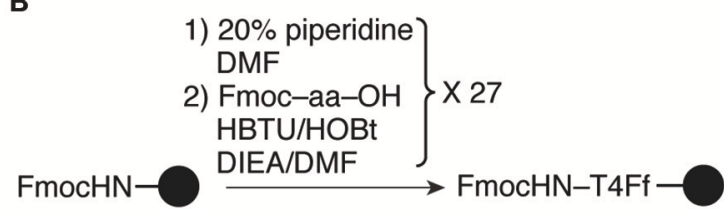

ChemMatrix<smiles>O=C(CCNC(F)F)Nc1ccc(-c2ccc(C(=O)O)cn2)nc1</smiles>

1) $20 \%$ piperidine

2) Fmoc- $\beta$ AlaBpy-OH $\} \times 2$ HATU, DIEA/DMF

3) $30 \%$ piperidine

4) $\mathrm{Ac}_{2} \mathrm{O}$, DIEA/DMF

5) TFA, $\mathrm{CH}_{2} \mathrm{Cl}_{2}$, TIS, H2O (90:5:2.5:2.5)

(BAlaBpy) ${ }_{2}-\mathrm{T4Ff}$

Fmoc-ßAlaBpy-OH (1)

FIGURE 1 | (A) Structural elements and sequence of the natural T4Ff, and proposed structure of the ( $\boldsymbol{\beta} \mathbf{A l a B p y})_{\mathbf{2}}$-T4Ff helicate at the N-terminus of the T4Ff scaffold. The three chains of the T4Ff are shown with different colors (orange, blue, light gray) for clarity. The $\Lambda \Lambda$ - chirality is induced by the natural twisting of the T4Ff $\mathrm{N}$-terminal polyproline helices. (B) Synthetic procedure for obtaining the T4Ff helicates, and structure of the chelating Fmoc- $\beta$ AlaBpy-OH amino acid.

$K_{D 2}=6.6 \pm 0.7 \mu \mathrm{M}$, respectively (Figure 2, left; Kuzmic, 1996, 2009). UV/Vis titrations were also qualitatively consistent with the fluorescence data, showing a weak MLCT at about $535 \mathrm{~nm}$ in the presence of $\mathrm{Fe}(\mathrm{II})$ ions (See Supplementary Material). The formation of the expected $\left.\left[(\boldsymbol{\beta A l a B p y})_{2}-\mathbf{T} 4 \mathbf{F f}\right]_{3} \mathrm{Fe}_{2}\right]^{4+}$ complex was also confirmed by mass spectrometry of the final solution of the titrations, which showed a peak at the expected mass of the molecular ion $(\mathrm{m} / z=11084.6)$.

In order to study the chirality induction around the metal centers we measured the circular dichroism spectra of the trimeric $\left[(\boldsymbol{\beta A l a B p y})_{2}-\mathbf{T} 4 \mathbf{F f}\right]_{3}$ ligand, and its $\mathrm{Fe}(\mathrm{II})$ complex $\left[(\boldsymbol{\beta A l a B p y})_{2}-\mathbf{T} 4 \mathbf{F f}\right]_{3} \mathrm{Fe}_{2}^{+4}$. As expected from the original structural analysis, the observed positive Cotton effect at c.a. $330 \mathrm{~nm}$ is consistent with the formation of a $\Lambda \Lambda$-helicate. Furthermore, the small change in the CD spectra upon addition of $\mathrm{Fe}$ (II) also suggests that the bipyridine ligands are strongly preorganized, even in absence of the metal, and that only a small rearrangement of the chromophores takes place upon coordination (Figure 2, right). This is consistent with earlier computational studies with related bis-bipyridyl peptide ligands, which showed that the bipyridine residues have a large tendency to stack on top of each other (Rama et al.,
2012). This stacking interaction will presumably rigidify the bisbipyridyl trimer and facilitate the helical induction by the foldon domain.

In order to gain some insight into the structure and stability of the peptide helicate we performed Molecular Dynamics (MD) simulations in explicit solvent and periodic boundary conditions (see Methods section for details). The structure of the $\Lambda \Lambda$ $\left[(\boldsymbol{\beta A l a B p y})_{2}-\mathbf{T} 4 \mathbf{F f}\right]_{3} \mathrm{Fe}_{2}^{+4}$ unit appears highly stable along all the $\mathrm{MD}$ trajectory retaining its helicity conformation and the $\mathrm{Fe}$ (II) octahedral coordination geometry. Moreover, the T4Ff scaffold appears stable during the simulation showing no appreciable deformations as a result of the introduction of the artifical $(\beta \mathrm{AlaBpy})_{2}$ unit. The root-mean square deviation (RMSD) of the whole system was computed along the MD using the minimized initial structures as a reference, the trajectories attain relative stable RMSD after the first $\sim 20$ ns, that reach up to $1.99 \pm 0.62$ $\AA$ in average (See Supplementary Material). A cluster analysis was performed on the full length MD experiments showing a predominant conformations occupying about $\sim 40 \%$ of the total conformation repartition. Overall, the results highlight that the computed model is very stable along the $100 n s$ of the MD and results consistent with the experimental data. Interestingly, the 

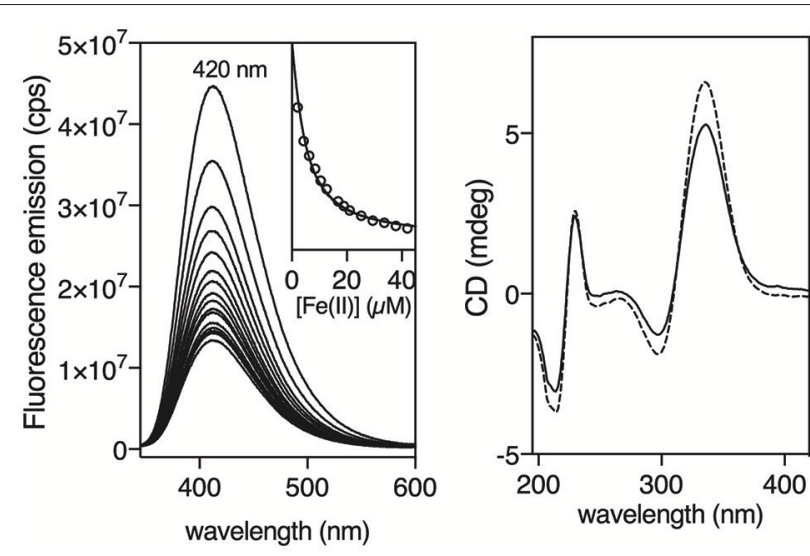

FIGURE 2 | Fluorescence titration of a $3 \mu \mathrm{M}(9 \mu \mathrm{M}$ monomer) solution of $\left[(\boldsymbol{\beta A l a B p y})_{\mathbf{2}}-\mathbf{T} \mathbf{4} \mathbf{F f}\right]_{3}$ with increasing concentrations of $\mathrm{Fe}(\mathrm{II})$. Inset shows emission at $420 \mathrm{~nm}$ upon excitation at $305 \mathrm{~nm}$ with increasing concentrations of $\mathrm{Fe}(\mathrm{II})$, and the best fit to a 1:2 binding mode (Hellman and Fried, 2007;

Peberdy et al., 2007). Experiments were made in triplicate. Right. Circular Dichroism of a $6 \mu \mathrm{M}$ solution $\left(18 \mu \mathrm{M}\right.$ monomer) of $\left[(\boldsymbol{\beta A l a B p y})_{\mathbf{2}}-\mathbf{T} \mathbf{4} \mathbf{F f}\right]_{3}$ (dashed line) and in the presence of $90 \mu \mathrm{M}$ Fe(II) (solid line). All experiments were made in $1 \mathrm{mM}$ phosphate buffer, $\mathrm{pH} 6.5,10 \mathrm{mM} \mathrm{NaCl}$ at $20^{\circ} \mathrm{C}$.
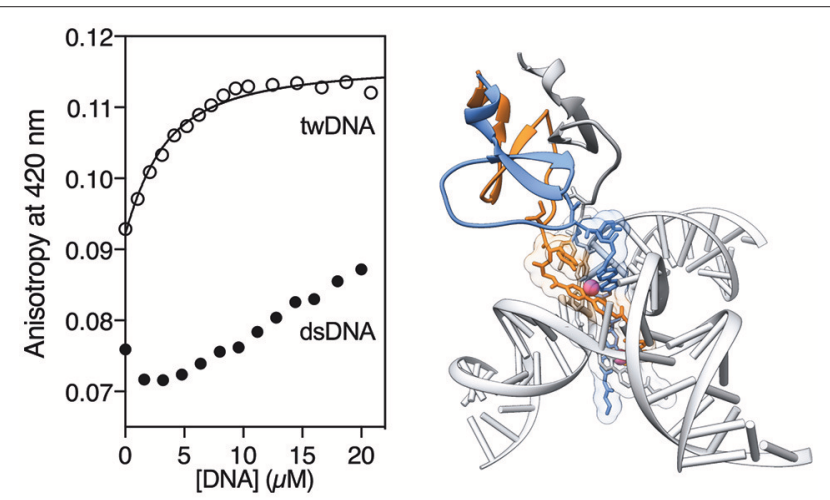

FIGURE 3 | First cluster representative frame of the MD trajectory for the $\Lambda \Lambda$-[(BAlaBpy $\left.)_{2}-\mathbf{T} \mathbf{4} \mathbf{F f}\right]_{3} \mathrm{Fe}_{2}^{+4}$ system showing the stable structure of the T4Ff domain. Note the flexible hinge region between the rigid helicate and the T4Ff domain.

MD analysis revealed a hinge region with increased flexibility connecting the more rigid helicate and foldon domains, which suggests the replacement of the $\mathrm{N}$-terminal Gly reside for a more conformationally restricted residue in future designs.

Having made a preliminary characterization of the T4Ff helicate, we studied its DNA binding properties by titrating a $2 \mu \mathrm{M}$ solution of $\left[(\boldsymbol{\beta A l a B p y})_{2}-\mathbf{T} 4 \mathbf{F f}\right]_{3}(6 \mu \mathrm{M}$ mononer $)$ in the presence of saturating concentrations of $\mathrm{Fe}$ (II) according to the previous fluorescence titrations $(20 \mu \mathrm{M})$ with increasing concentrations of a three-way DNA junction (tw-DNA), and measuring the fluorescence anisotropy of the bipyridine fluorophores at $420 \mathrm{~nm}$ after each addition of DNA. The titration profile could be fitted to a 1:1 binding mode, with a

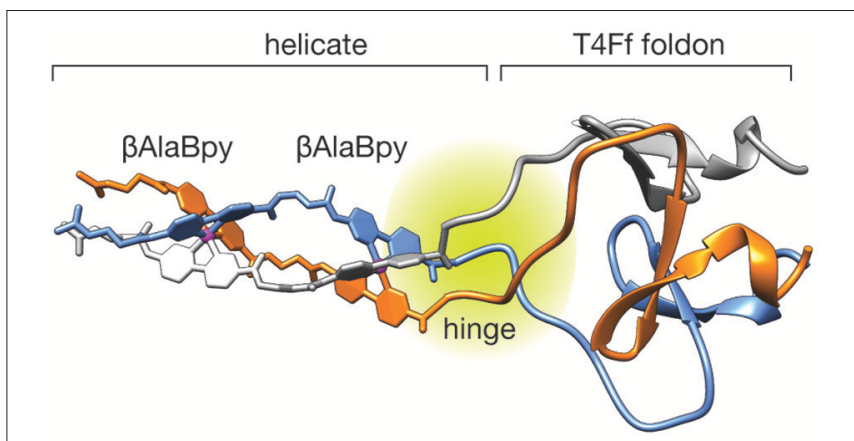

FIGURE 4 | (Left) Anisotropy titration of [( $\left.(\boldsymbol{A A l a B p y})_{\mathbf{2}}-\mathbf{T} \mathbf{4} \mathbf{F f}\right]_{3} \mathrm{Fe}_{2}$ in $1 \mathrm{mM}$ phosphate buffer, $10 \mathrm{mM} \mathrm{NaCl}$ with increasing concentrations of tw-DNA. The best fit to a 1:1 binding mode is shown (curve fitting was performed using DynaFit).(Kuzmic, 1996, 2009) tw-DNA sequences: 5'-CAC CGC TCT GGT CCT C-3'; 5'-CAG GCT GTG AGC GGT G-3'; 5'-GAG GAC CAA CAG CCT G-3'. Right: Model of the interaction between the $\left[(\boldsymbol{\beta A l a B p y})_{\mathbf{2}}-\mathbf{T} \mathbf{4} \mathbf{F f}\right]_{3} \mathrm{Fe}_{2}$ and the three-way junction, based on the reported pdb structures of an helicate bound to a three-way junction (pdb code $4 \mathrm{NCU}$ ), and the structure of the fibritin foldon (pdb code 2ETO; Oleksy et al., 2006).

dissociation constant of $2.17 \pm 0.45 \mu \mathrm{M}$ of the $\left[(\boldsymbol{\beta A l a B p y})_{2}\right.$ T4Ff $]_{3} \mathrm{Fe}_{2}$ complex to tw-DNA. Titrations under the same conditions with a model double stranded DNA (ds-DNA) led to a small, monotonic increase in the anisotropy, which is in tune with the the formation of weak complexes or non-specific binding (Figure 3). The low affinity to dsDNA is consistent with previous studies with other helicates (Figure 4; Tuma et al., 1999; Oleksy et al., 2006; Gamba et al., 2016). Control titrations adding with $\left[(\boldsymbol{\beta A l a B p y})_{2}-\mathbf{T} \mathbf{4 F f}\right]_{3}$ foldon in absence of metal did not show any response to added DNA (See Supplementary Material), thus confirming that the formation of the helicate structure is required for DNA recognition, and the foldon only have a structural role in the formation of the helicate.

In addition to the spectroscopic studies, we also studied the DNA binding properties of the $\left[(\boldsymbol{\beta A l a B p y})_{2}-\mathbf{T} 4 \mathbf{F f}\right]_{3} \mathrm{Fe}_{2}$ helicate by electrophoretic mobility assays (EMSA) in polyacrylamide gel under non-denaturing conditions (Liebler and Diederichsen, 2004), visualizing the DNA in the gel using SybrGold staining (Vázquez et al., 2007). In agreement with the fluorescence titration studies discussed previously, incubation of the target tw-DNA with the $\left[(\boldsymbol{\beta A l a B p y})_{2}-\mathbf{T} 4 \mathbf{F f}\right]_{3} \mathrm{Fe}_{2}$ helicate resulted in the concentration-dependent appearance of a new retarded band, which is consistent with the formation of the expected tw-DNA/ $\left[(\boldsymbol{\beta A l a B p y})_{2}-\mathrm{T} 4 \mathrm{Ff}\right]_{3} \mathrm{Fe}_{2}$ complex (Figure 5, lanes 16). Additionally, the overall intensity of the lanes of the gel is progressively reduced in the presence of increasing concentrations of the $\left[(\boldsymbol{\beta A l a B p y})_{2}-\mathbf{T} 4 \mathbf{F f}\right]_{3} \mathrm{Fe}_{2}$ complex, which suggests the formation of higher-order aggregates with the threeway junction DNA in the gel conditions (Chanvorachote et al., 2009; Thordarson, 2010). On the other hand, incubation of a model double-stranded DNA with the peptide helicate did not show any new slow-migrating bands (Figure 5, lanes 7-10), which is in agreement with the expected low affinity for this form of DNA, and demonstrates that the small increase observed 


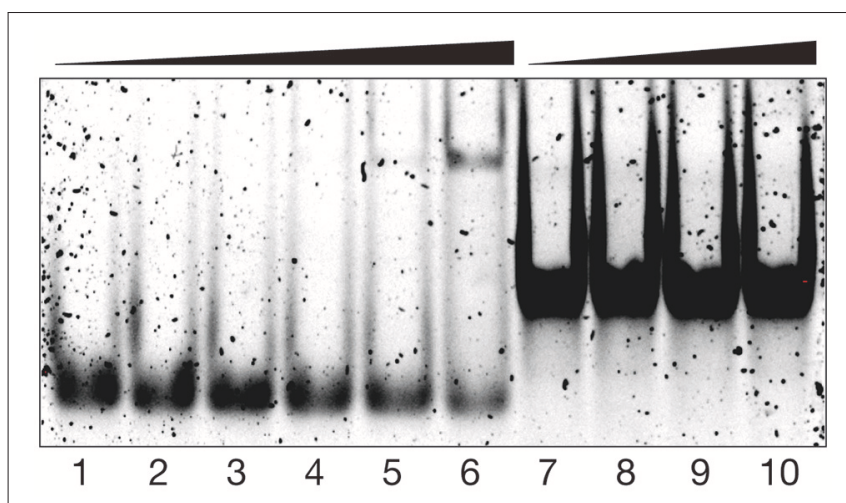

FIGURE 5 | EMSA DNA binding studies results for [( $\boldsymbol{\beta A l a B p y})_{\mathbf{2}} \mathbf{- T 4} \mathbf{T} \mathbf{f}_{3} \mathrm{Fe}_{2}$ helicate. Lanes 1-6, $200 \mathrm{nM}$ tw-Rho-DNA with 0, 150, 250, 500, 1,000, and $2,000 \mathrm{nM}$ of $\left[(\boldsymbol{\beta A l a B p y})_{\mathbf{2}}-\mathbf{T} \mathbf{T F f}\right]_{3}$ and $14 \mathrm{eq}$. of $(\mathrm{NH} 4)_{2} \mathrm{Fe}\left(\mathrm{SO}_{4}\right)_{2} \bullet 6 \mathrm{H}_{2} \mathrm{O}$ in each lane; lanes 7-10, $200 \mathrm{nM}$ dsDNA with 0, 500, 1,000, and 2,000 nM of $\left[(\boldsymbol{\beta A l a B p y})_{\mathbf{2}}-\mathbf{T} \mathbf{4 F f}\right]_{3}$ and $14 \mathrm{eq}$. of $(\mathrm{NH} 4)_{2} \mathrm{Fe}\left(\mathrm{SO}_{4}\right)_{2} \bullet 6 \mathrm{H}_{2} \mathrm{O}$ in each lane. Samples were resolved on a $10 \%$ nondenaturing polyacrylamide gel and $1 \times$ TBE buffer over $35 \mathrm{~min}$ at $25^{\circ} \mathrm{C}$, and stained with SyBrGold $(5 \mu \mathrm{L}$ in $50 \mathrm{~mL}$ of $0.5 \times \mathrm{TBE})$ for $10 \mathrm{~min}$, followed by fluorescence visualization. Oligonucleotide sequences: tw-DNA, 5'-CAC CGC TCT GGT CCT C-3'; 5'-CAG GCT GTG AGC GGT G-3'; 5'-GAG GAC CAA CAG CCT G-3'; dsDNA (only one strand shown) 5'-AAC ACA TGC AGG ACG GCG CTT-3'.

in the fluorescence anisotropy titration of dsDNA (Figure 4) arises from weak interactions that are not seen at the lower concentrations used in the EMSA experiment.

\section{CONCLUSIONS}

In summary, we have shown the potential of small protein domains for the precise structural organization of coordination complexes. Modification of the T4 Fibritin foldon with metalchelating bipyridines results allows the assembly of unique three-strand helicates in which the parallel orientation of the three helicate ligands is directed by the self-assembled T4Ff domain, and the chirality of the dinuclear helicate ( $M$ helicity or $\Lambda \Lambda$-configuration in the metal complexes) is selected by the relative orientation of the natural polyproline helices at the $\mathrm{N}$ terminus of the T4Ff trimer. The final supramolecular peptide

\section{REFERENCES}

Albrecht, M. (2001). "Let's Twist Again” double-stranded, triple-stranded, and circular helicates. Chem. Rev. 101, 3457-3497. doi: 10.1021/cr0103672

Albrecht, M. (2005). Artificial molecular double-stranded helices. Angew. Chem. Int. Ed. Engl. 44, 6448-6451. doi: 10.1002/anie.200501472

Apostolovic, B., Danial, M., and Klok, H.-A. (2010). Coiled coils: attractive protein folding motifs for the fabrication of self-assembled, responsive and bioactive materials. Chem. Soc. Rev. 39, 3541-3575. doi: 10.1039/b914339b

Ball, Z. T. (2013). Designing enzyme-like catalysts: a rhodium(II) metallopeptide case study. Acc. Chem. Res. 46, 560-570. doi: 10.1021/ar300261h

Bayly, C. I., Cieplak, P., Cornell, W., and Kollman, P. A. (1993). A wellbehaved electrostatic potential based method using charge restraints for deriving atomic charges: the resp model. J. Phys. Chem. 97, 10269-10280. doi: $10.1021 / \mathrm{j} 100142 \mathrm{a} 004$ helicate $\left[(\boldsymbol{\beta A l a B p y})_{2} \text {-T4Ff }\right]_{3} \mathrm{Fe}_{2}$ displays good in vitro DNA binding and selectivity toward three-way DNA junctions. We are currently exploring alternative peptide sequences to improve the solubility of the peptide/DNA complexes, and modifications with positively charged residues that might increase the overall affinity.

\section{AUTHOR CONTRIBUTIONS}

JG-G and DGP performed the experimental work (synthesis of the bipyridine building block, peptide synthesis, metal and DNA binding studies), GB did preliminary studies with the ( $\beta$ AlaBpy)2-T4Ff peptide. GS and J-DM did the computational work and contributed to the preparation of the final manuscript. MVL and MEV conceived the project, supervised the experimental work. MEV wrote the manuscript with the collaboration of MVL, and prepared the graphic material.

\section{ACKNOWLEDGMENTS}

Financial support from the Spanish grants CTQ2015-70698-R, CTQ2017-87889-P, the Xunta de Galicia (Centro singular de investigación de Galicia accreditation 2016-2019, ED431G/09) and the European Union (European Regional Development Fund - ERDF), is gratefully acknowledged. JG-G, thanks the Spanish MINECO for his FPI fellowship, GB thanks the ERC for her EU METALIC-II 2013-2442/001-001-EMA2 mobility scheme fellowship, and GS. thanks the Universitat Autònoma de Barcelona for its support to his PhD. J-DM and GS are thankful for the support given by the Generalitat de Catalunya 2017SGR1323. Support of COST Action CM1306 is kindly acknowledged. MEV, also wish to acknowledge the generous support by the Fundación Asociación Española Contra el Cáncer AECC (IDEAS197VAZQ grant).

\section{SUPPLEMENTARY MATERIAL}

The Supplementary Material for this article can be found online at: https://www.frontiersin.org/articles/10.3389/fchem. 2018.00520/full\#supplementary-material

Berthelmann, A., Lach, J., Gräwert, M. A., Groll, M., and Eichler, J. (2014). Versatile $\mathrm{C}(3)$-symmetric scaffolds and their use for covalent stabilization of the foldon trimer. Org. Biomol. Chem. 12, 2606-2614. doi: 10.1039/C3OB42251H

Berwick, M. R., Lewis, D. J., Jones, A. W., Parslow, R. A., Dafforn, T. R., Cooper, H. J., et al. (2014). De novo design of $\operatorname{Ln}(\mathrm{III})$ coiled coils for imaging applications. J. Am. Chem. Soc. 136, 1166-1169. doi: 10.1021/ja408741h

Boyle, A. L., and Woolfson, D. N. (2011). De novo designed peptides for biological applications. Chem. Soc. Rev. 40, 4295-4306. doi: 10.1039/c0cs00152j

Cardo, L., Sadovnikova, V., Phongtongpasuk, S., Hodges, N. J., and Hannon, M. J. (2011). Arginine conjugates of metallo-supramolecular cylinders prescribe helicity and enhance DNA junction binding and cellular activity. Chem. Commun. 47, 6575-6577. doi: 10.1039/c1cc11356a

Case, D. A., Botello-Smith, R. M. B. W., Cerutti, D. S., Cheatham, T. E., Darden T. A. III, Duke, R. E. et al. (2016). Kollman Amber 16, San Francisco: University of California. 
Chanvorachote, B., Nimmannit, U., Muangsiri, W., and Kirsch, L. (2009). An evaluation of a fluorometric method for determining binding parameters of drug-carrier complexes using mathematical models based on total drug concentration. J. Fluoresc. 19, 747-753. doi: 10.1007/s10895-009-0471-1

Chen, W., Tang, X., Dou, W., Wang, B., Guo, L., Ju, Z., et al. (2017). The Construction of Homochiral lanthanide quadruple-stranded helicates with multiresponsive sensing properties toward fluoride anions. Chem. Eur. J. 23, 9804-9811. doi: 10.1002/chem.201700827

Coin, I., Beyermann, M., and Bienert, M. (2007). Solid-phase peptide synthesis: from standard procedures to the synthesis of difficult sequences. Nat. Protoc. 2, 3247-3256. doi: 10.1038/nprot.2007.454

Dhanya, S., and Bhattacharyya, P. K. (1992). Fluorescence behaviour of 2,2' bipyridine in aqueous solution. J. Photochem. Photobiol. A Chem. 63, 179-185. doi: 10.1016/1010-6030(92)85134-G

Dong, Y., Liu, T., Wan, X., Pei, H., Wu, L., and Yao, Y. (2017). Facile onepot synthesis of bipyridine-based dual-channel chemosensor for the highly selective and sensitive detection of aluminum ion. Sens. Actuators B Chem. 241, 1139-1144 doi: 10.1016/j.snb.2016.10.022

Du, L., Leung, V. H., Zhang, X., Zhou, J., Chen, M., He, W., et al. (2011). A recombinant vaccine of $\mathrm{H} 5 \mathrm{~N} 1 \mathrm{HA} 1$ fused with foldon and human IgG Fc induced complete cross-clade protection against divergent $\mathrm{H} 5 \mathrm{~N} 1$ viruses. PLoS ONE 6:e16555. doi: 10.1371/journal.pone.0016555

Eastman, P., Swails, J., Chodera, J. D., McGibbon, R. T., Zhao, Y., Beauchamp, K. A., et al. (2017). Openmm 7: rapid development of high performance algorithms for molecular dynamics. PLoS Comput. Biol. 13:e1005659. doi: 10.1371/journal.pcbi.1005659

Ehlers, A., Böhme, M., Dapprich, S., Gobbi, A., Höllwarth, A., Jonas, V., et al. (1993). A set of f-polarization functions for pseudo-potential basis sets of the transition metals sc-cu, y-ag and la-au. Chem. Phys. Lett. 208, 111-114. doi: 10.1016/0009-2614(93)80086-5

Frisch, M. J., Trucks, G. W., Schlegel, H. B., Scuseria, G. E., Robb, M. A., Cheeseman, J. R., et al. (2010). Gaussian 09, Revision c.01. Wallingford, CT: Gaussian, Inc.

Gamba, I., Rama, G., Ortega-Carrasco, E., Berardozzi, R., Sánchez-Pedregal, V. M., Di Bari, L., et al. (2016). The folding of a metallopeptide. Dalton Trans. 45, 881-885. doi: 10.1039/C5DT02797G

Gamba, I., Rama, G., Ortega-Carrasco, E., Maréchal, J.-D., Martínez-Costas, J., Vázquez, M. E., et al. (2014). Programmed stereoselective assembly of DNA-binding helical metallopeptides. Chem. Commun. 50, 11097-11100. doi: 10.1039/C4CC03606A

Gamba, I., Salvadó, I., Rama, G., Bertazzon, M., Sánchez, M. I., Sánchez-Pedregal, V. M., et al. (2013). Custom-fit ruthenium(II) metallopeptides: a new twist to DNA binding with coordination compounds. Chem. Eur. J. 19, 13369-13375. doi: 10.1002/chem.201301629

Gazit, E. (2007). Self-assembled peptide nanostructures: the design of molecular building blocks and their technological utilization. Chem. Soc. Rev. 36, 1263-1269. doi: 10.1039/b605536m

Ghadiri, M. R., Soares, C., and Choi, C. (1992). Design of an artificial four-helix bundle metalloprotein via a novel ruthenium(II)-assisted self-assembly process. J. Am. Chem. Soc. 114, 4000-4002. doi: 10.1021/ja00036a072

Guan, Y., Du, Z., Gao, N., Cao, Y., Wang, X., Scott, P., et al. (2018). Stereochemistry and amyloid inhibition: asymmetric triplex metallohelices enantioselectively bind to A $\beta$ peptide. Sci. Adv. 4:eaao6718. doi: 10.1126/sciadv.aao6718

Güthe, S., Kapinos, L., Möglich, A., Meier, S., Grzesiek, S., and Kiefhaber, T. (2004). Very fast folding and association of a trimerization domain from bacteriophage T4 fibritin. J. Mol. Biol. 337, 905-915. doi: 10.1016/j.jmb.2004.02.020

Habazettl, J., Reiner, A., and Kiefhaber, T. (2009). NMR structure of a monomeric intermediate on the evolutionarily optimized assembly pathway of a small trimerization domain. J. Mol. Biol. 389, 103-114. doi: 10.1016/j.jmb.2009.03.073

Haino, T., Shio, H., Takano, R., and Fukazawa, Y. (2009). Asymmetric induction of supramolecular helicity in calix[4]arene-based triple-stranded helicate. Chem. Commun. 2009, 2481-2483. doi: 10.1039/B900599D

Hellman, L. M., and Fried, M. G. (2007). Electrophoretic mobility shift assay (EMSA) for detecting protein-nucleic acid interactions. Nat. Protoc. 2, 1849-1861. doi: 10.1038/nprot.2007.249

Hornak, V., Abel, R., Okur, A., Strockbine, B., Roitberg, A., and Simmerling, C. (2006). Comparison of multiple amber force fields and development of improved protein backbone parameters. Proteins Struct. Funct. Bioinf. 65, 712-725. doi: 10.1002/prot.21123

Howson, S. E., Bolhuis, A., Brabec, V., Clarkson, G. J., Malina, J., Rodger, A., et al. (2012). Optically pure, water-stable metallo-helical "flexicate" assemblies with antibiotic activity. Nat. Chem. 4, 31-36. doi: 10.1038/nchem.1206

Ishida, H., Maruyama, Y., Kyakuno, M., Kodera, Y., Maeda, T., and Oishi, S. (2006). Artificial metalloproteins with a ruthenium tris(bipyridyl) complex as the core. Chembiochem 7, 1567-1570. doi: 10.1002/cbic.200600162

Kaes, C., Katz, A., and Hosseini, M. W. (2000). Bipyridine: the most widely used ligand. A review of molecules comprising at least two 2,2'-bipyridine units. Chem. Rev. 100, 3553-3590. doi: 10.1021/cr990376z

Kaner, R. A., Allison, S. J., Faulkner, A. D., Phillips, R. M., Roper, D. I., Shepherd, S. L., et al. (2015). Anticancer metallohelices: nanomolar potency and high selectivity. Chem. Sci. 7, 951-958. doi: 10.1039/C5SC03677A

Kobayashi, N., Yanase, K., Sato, T., Unzai, S., Hecht, M. H., and Arai, R. (2015). Self-assembling nano-architectures created from a protein nano-building block using an intermolecularly folded dimeric de novo protein. J. Am. Chem. Soc. 137, 11285-11293. doi: 10.1021/jacs.5b03593

Kuzmic, P. (1996). Program DYNAFIT for the analysis of enzyme kinetic data: application to HIV proteinase. Anal. Biochem. 237, 260-273. doi: 10.1006/abio.1996.0238

Kuzmic, P. (2009). DynaFit-a software package for enzymology. Methods Enzymol. 467, 247-280. doi: 10.1016/S0076-6879(09)67010-5

Lai, Y.-T., King, N. P., and Yeates, T. O. (2012). Principles for designing ordered protein assemblies. Trends Cell Biol. 22, 653-661. doi: 10.1016/j.tcb.2012.08.004

Lehn, J. M., Rigault, A., Siegel, J., Harrowfield, J., Chevrier, B., and Moras, D. (1987). Spontaneous assembly of double-stranded helicates from oligobipyridine ligands and copper(I) cations: structure of an inorganic double helix. Proc. Natl. Acad. Sci. U.S.A. 84:2565. doi: 10.1073/pnas.84.9.2565

Li, P., and Merz, K. M. Jr. (2016). MCPB.py: a python based metal center parameter builder. J. Chem. Inf. Model. 56, 599-604. doi: 10.1021/acs.jcim.5b00674

Li, X., Suzuki, K., Kashiwada, A., Hiroaki, H., Kohda, D., and Tanaka, T. (2000). Soft metal ions, $\mathrm{Cd}(\mathrm{II})$ and $\mathrm{Hg}$ (II), induce triple-stranded $\alpha$-helical assembly and folding of a de novo designed peptide in their trigonal geometries. Protein Sci. 9, 1327-1333. doi: 10.1110/ps.9.7.1327

Lieberman, M., and Sasaki, T. (1991). Iron(II) organizes a synthetic peptide into three-helix bundles. J. Am. Chem. Soc. 113, 1470-1471. doi: $10.1021 / \mathrm{ja} 00004 \mathrm{a} 090$

Liebler, E. K., and Diederichsen, U. (2004). From IHF protein to design and synthesis of a sequence-specific DNA bending peptide. Org. Lett. 6, 2893-2896. doi: 10.1021/ol049016a

Luo, X., Wang, T. A., Zhang, Y., Wang, F., and Schultz, P. G. (2016). Stabilizing protein motifs with a genetically encoded metal-ion chelator. Cell Chem Biol. 23, 1098-1102. doi: 10.1016/j.chembiol.2016.08.007

Matsuura, K., Hayashi, H., Murasato, K., and Kimizuka, N. (2010). Trigonal tryptophane zipper as a novel building block for $\mathrm{pH}$-responsive peptide nanoassemblies. Chem. Commun. 47, 265-267. doi: 10.1039/C0CC01324B

Matsuura, K., Murasato, K., and Kimizuka, N. (2005). Artificial peptidenanospheres self-assembled from three-way junctions of $\beta$-sheet-forming peptides. J. Am. Chem. Soc. 127, 10148-10149. doi: 10.1021/ja052644i

Mitchell, D. E., Clarkson, G., Fox, D. J., Vipond, R. A., Scott, P., and Gibson, M. I. (2017). Antifreeze protein mimetic metallohelices with potent ice recrystallization inhibition activity. J. Am. Chem. Soc. 139, 9835-9838. doi: $10.1021 /$ jacs.7b05822

Newkome, G. R., Gross, J., and Patri, A. K. (1997). Synthesis of unsymmetrical 5,5'-disubstituted 2,2'-Bipyridines1. J. Org. Chem. 62, 3013-3014.

Oleksy, A., Blanco, A. G., Boer, R., Usón, I., Aymam,í, J., Rodger, A., et al. (2006). Molecular recognition of a three-way DNA junction by a metallosupramolecular helicate. Angew. Chem. Int. Ed. 45, 1227-1231. doi: 10.1002/anie.200503822

Papanikolopoulou, K., Teixeira, S., Belrhali, H., Forsyth, V. T., Mitraki, A., and van Raaij, M. J. (2004). Adenovirus fibre shaft sequences fold into the native triple $\beta$-spiral fold when $\mathrm{N}$-terminally fused to the bacteriophage T4 fibritin foldon trimerisation motif. J. Mol. Biol. 342, 219-227. doi: 10.1016/j.jmb.2004.07.008

Pazos, E., Sleep, E., Rubert Pérez, C. M., Lee, S. S., Tantakitti, F., and Stupp, S. I. (2016). Nucleation and growth of ordered arrays of silver nanoparticles on peptide nanofibers: hybrid nanostructures with antimicrobial properties. J. Am. Chem. Soc. 138, 5507-5510. doi: 10.1021/jacs.6b01570 
Peacock, A. F., Bullen, G. A., Gethings, L. A., Williams, J. P., Kriel, F. H., and Coates, J. (2012). Gold-phosphine binding to de novo designed coiled coil peptides. J. Inorg. Biochem. 117, 298-305. doi: 10.1016/j.jinorgbio.2012.05.010

Peberdy, J. C., Malina, J., Khalid, S., Hannon, M. J., and Rodger, A. (2007). Influence of surface shape on DNA binding of bimetallo helicates. J. Inorg. Biochem. 101, 1937-1945. doi: 10.1016/j.jinorgbio.2007.07.005

Pedregal, J. R.-G., Alonso-Cotchico, L., Velasco, L., and Maréchal, J.-D. (2018). OMMProtocol: A Command Line Application to Launch Molecular Dynamics Simulations With OpenMM. Available online at: http://bit.ly/2CN0khh

Pettersen, E. F., Goddard, T. D., Huang, C. C., Couch, G. S., Greenblatt, D. M., Meng, E. C., et al. (2004). Ucsf chimera-a visualization system for exploratory research and analysis. J. Comput. Chem. 25, 1605-1612. doi: 10.1002/jcc.20084

Piguet, C., Bernardinelli, G., and Hopfgartner, G. (1997). Helicates as versatile supramolecular complexes. Chem. Rev. 97, 2005-2062. doi: 10.1021/cr96 $0053 \mathrm{~s}$

Rama, G., Ardá, A., Maréchal, J-D., Gamba, I., Ishida, H., Jiménez-Barbero, J., et al. (2012). Stereoselective formation of chiral metallopeptides. Chem. Eur. J. 18, 7030-7035. doi: 10.1002/chem.201201036

Robson Marsden, H., and Kros, A. (2010). Self-assembly of coiled coils in synthetic biology: inspiration and progress. Angew. Chem. Int. Ed. 49, 2988-3005. doi: 10.1002/anie.200904943

Salvadó, I., Gamba, I., Montenegro, J., Martínez-Costas, J., Brea, J. M., Loza, M. I., et al. (2016). Membrane-disrupting iridium(iii) oligocationic organometallopeptides. Chem. Commun. 52, 11008-11011. doi: 10.1039/C6CC05537K

Stetefeld, J., Frank, S., Jenny, M., Schulthess, T., Kammerer, R. A., Boudko, S., et al. (2003). Collagen stabilization at atomic level: crystal structure of designed (GlyProPro)10foldon. Structure 11, 339-346. doi: 10.1016/S0969-2126(03)00025-X

Tao, Y., Strelkov, S. V., Mesyanzhinov, V. V., and Rossmann, M. G. (1997). Structure of bacteriophage T4 fibritin: a segmented coiled coil and the role of the C-terminal domain. Structure 5, 789-798. doi: 10.1016/S0969-2126(97)00233-5

Thordarson, P. (2010). Determining association constants from titration experiments in supramolecular chemistry. Chem. Soc. Rev. 40, 1305-1323. doi: $10.1039 / \mathrm{C} 0 \mathrm{CS} 00062 \mathrm{~K}$
Torrado, A., Walkup, G. K., and Imperiali, B. (1998). Exploiting polypeptide motifs for the design of selective $\mathrm{Cu}(\mathrm{II})$ ion chemosensors. J. Am. Chem. Soc. 120, 609-610. doi: 10.1021/ja973357k

Tuma, R. S., Beaudet, M. P., Jin, X., Jones, L. J., Cheung, C. Y., Yue, S., et al. (1999). Characterization of SYBR Gold nucleic acid gel stain: a dye optimized for use with 300-nm ultraviolet transilluminators. Anal. Biochem. 268, 278-288. doi: 10.1006/abio.1998.3067

Ulijn, R. V., and Smith, A. M. (2008). Designing peptide based nanomaterials. Chem. Soc. Rev. 37, 664-675. doi: 10.1039/b60 $9047 \mathrm{~h}$

Vázquez, O., Vázquez, M. E., Blanco, J. B., Castedo, L., and Mascareñas, J. L. (2007). Specific DNA recognition by a synthetic, monomeric Cys2His2 zinc-finger peptide conjugated to a minor-groove binder. Angew. Chem. Int. Ed Engl. 46, 6886-6890. doi: 10.1002/anie.2007 02345

Yagi, M., Kaneshima, T., Wada, Y., Takemura, K., and Yokoyama, Y. (1994). The effects of conformation and coordination to zinc(II) ions on the luminescence properties of $2,2^{\prime}$-bipyridine, methyl-substituted $2,2^{\prime}$ bipyridines and 2,2' -biquinoline. J. Photochem. Photobiol. A Chem. 84, 27-32. doi: 10.1016/1010-6030(94)03842-2

Yanai, T., Tew, D. P., and Handy, N. C. (2004). A new hybrid exchangecorrelation functional using the coulomb-attenuating method (camb3lyp). Chem. Phys. Lett. 393, 51-57. doi: 10.1016/j.cplett.2004. 06.011

Conflict of Interest Statement: The authors declare that the research was conducted in the absence of any commercial or financial relationships that could be construed as a potential conflict of interest.

Copyright (C) 2018 Gómez-González, Peña, Barka, Sciortino, Maréchal, Vázquez López and Vázquez. This is an open-access article distributed under the terms of the Creative Commons Attribution License (CC BY). The use, distribution or reproduction in other forums is permitted, provided the original author(s) and the copyright owner(s) are credited and that the original publication in this journal is cited, in accordance with accepted academic practice. No use, distribution or reproduction is permitted which does not comply with these terms. 